SUBJECT AREAS:

SOLAR CELLS

ORGANIC-INORGANIC NANOSTRUCTURES

Received

28 April 2014

Accepted

18 July 2014

Published

7 August 2014

Correspondence and requests for materials should be addressed to Q.H.L. (qhli@hqu.edu. $\mathrm{cn}$ ) or W.F.S. (weifu. sun518@gmail.com)

\section{Energy level control: toward an efficient hot electron transport}

\author{
Xiao Jin' ', Qinghua Li' ${ }^{1}$, Yue Li', Zihan Chen ', Tai-Huei Wei ${ }^{2}$, Xingdao He' \& Weifu Sun ${ }^{3}$
}

'Key Laboratory of Nondestructive Testing, Ministry of Education, Nanchang Hangkong University, Nanchang, 330063, P. R. China, ${ }^{2}$ Department of Physics, National Chung-Cheng University, Chia-Yi 62 1, Taiwan, Republic of China, ${ }^{3}$ School of Materials Science and Engineering, The University of New South Wales, Sydney, NSW 2052, Australia.

Highly efficient hot electron transport represents one of the most important properties required for applications in photovoltaic devices. Whereas the fabrication of efficient hot electron capture and lost-cost devices remains a technological challenge, regulating the energy level of acceptor-donor system through the incorporation of foreign ions using the solution-processed technique is one of the most promising strategies to overcome this obstacle. Here we present a versatile acceptor-donor system by incorporating $\mathrm{MoO}_{3}: \mathrm{Eu}$ nanophosphors, which reduces both the 'excess' energy offset between the conduction band of acceptor and the lowest unoccupied molecular orbital of donor, and that between the valence band and highest occupied molecular orbital. Strikingly, the hot electron transfer time has been shortened. This work demonstrates that suitable energy level alignment can be tuned to gain the higher hot electron/hole transport efficiency in a simple approach without the need for complicated architectures. This work builds up the foundation of engineering building blocks for third-generation solar cells.

ow-cost and high-efficiency photovoltaic cells have emerged as an important strategy to meet the cleanenergy demand of the twenty-first century ${ }^{1}$. Solution processing of polymer based inorganic/organic hybrid solar cells (HSCs) from semiconducting polymers is a promising approach to achieve this purpose. HSCs have attracted intensive interest for scientific research and industrial applications, owing to the relatively high electron mobility, good physicochemical stability of inorganic nanocrystals, and their potential applications for the production of flexible and large-area solar cells at potentially low cost ${ }^{2}$. Solution-processed inorganic/organic HSCs can take advantage of the beneficial properties of both types of materials, such as low-cost of solution processing of polymer semiconductors and high electron mobility of inorganic semiconductors ${ }^{3}$. As a relatively newly emerging hotspot, to attain the desirable efficiency of solar cells based on inorganic nanoparticles and a well-known conducting polymer poly(3-hexylthiophene) (P3HT) remains challenging and still in its infancy. Over the last five years, most of the reported power conversion efficiency (PCE) of solar cells based on P3HT is around $2 \%$, ranging from $1.7 \sim 3.0 \%$, depending on the type of inorganic nanocrystals, their morphology and others $^{4-8}$. Despite the advantages of inorganic/organic HSCs, the efficiencies of the HSCs are still low at the current stage of development, which restricts its potential practical applications. The present P3HT-based solar cells can absorb a large amount of solar light due to their small bandgap $(\sim 1.9 \mathrm{eV})$, which enables photons with low energy to create the necessary carriers and contribute to photocurrent ${ }^{9}$. However, the absorption of highenergy photons results in 'hot' electrons and holes, both of which are electronically excited and thermally activated, and lose most of their energy by emitting phonons (hot carrier cooling) without contributing to electric power ${ }^{10,11}$. Because of the initial cooling process, a substantial amount of solar energy has already been irreversibly lost. Efficient HSCs should absorb a wide range of photon energies and extract a large fraction of the energy to give high efficiencies by extracting 'hot' carriers before they thermalize to the band edges. Hence highly efficient bulkheterojunction $(\mathrm{BHJ})$ requires an accelerated transport rate of hot carrier to allow them to be extracted effectively before cooling down and do useful work through an external circuit. Researchers have demonstrated that it is possible to capture hot carriers while they're still in their high energy state before heat loss happens ${ }^{12-14}$. However, these hot carriers lose their energy so quickly (within several hundreds of picoseconds), how to capture these energetic carriers effectively becomes critically important. It is reported that the charge transfer processes at the interface of heterojunctions and the rate of these transfer processes are closely related to the energy level alignment between the materials at the interface ${ }^{15-17}$. An efficient strategy to enhance the efficiency by incorporating a foreign ion into inorganic semiconductors, which not only improves electron injection but suppresses the geminate recombination also ${ }^{18-21}$, has been revealed. On one hand, rare earth (RE) ion decorated $\mathrm{TiO}_{2}$ semiconductors have attracted much attention and have been proved an effective way to improve the perfor- 
mances of solar cells, owing to broadened absorption of the solar spectrum by down-conversion luminescence process of the RE ions $^{22-24}$. Moreover, RE compounds have exhibited long-lived excited states which potentially benefits hot electron/hole transport ${ }^{25,26}$. Although the excellent doping effects have been discovered before, nevertheless the detailed intrinsic driving force behind the good performance of solar cells by RE ion phosphors remains lacking. Especially, the crucial role of energy level regulation playing in charge transfer has not been clarified. On the other hand, molybdenum trioxide $\left(\mathrm{MoO}_{3}\right)$, recently emerged as a promising node material or cathode buffer, has demonstrated improved photoelectrochemical or photovoltaic performances due to its chemical inertness, strong photocatalytic performance, long-term photostability and low interfacial resistance ${ }^{27-29}$. Herein we incorporate $\mathrm{MoO}_{3}$ :Eu phosphor to decorate $\mathrm{TiO}_{2}$ nanocrystal, and expect that $\mathrm{MoO}_{3}$ : Eu nanocomposite can make use of the intriguing electronic properties of the both components to improve the photoexcited carrier transfer in HSCs.

In this report, the role of $\mathrm{MoO}_{3}$ :Eu phosphor in enhancing device performances was studied using both steady-state photoluminescence (PL) and transient PL spectroscopy. In details, the energy level control of acceptor by $\mathrm{MoO}_{3}$ :Eu phosphors and the corresponding influences on photoexcited carrier transfer were explored. Furthermore, the branching ratio between the competing relaxation pathways such as hot electron transfer, hot electron cooling and the geminate recombination of electron-hole pairs was quantified.

\section{Results}

Hot electron transport in BHJ. The primary process in almost all electronic solar energy conversion systems lies in incident solar energy induced electronic charge separation. On one hand, efficient energy transfer requires separation of these photoexcited electron-hole pairs into long-lived dissociated charges with a high quantum yield and minimal loss of free energy ${ }^{30-32}$. On the other hand, higher PCE also requires quickly extraction of hot electrons/ holes prior to the energy loss by cooling process. Suitable energy levels formation of donor, acceptor, and electrodes can improve the performance of solar cells $\mathrm{s}^{33-35}$, such as the reduction of the excess of lowest unoccupied molecular orbital (LUMO)-LUMO offset in P3HT-PCBM system ${ }^{36,37}$. It is known that the energy offset between conduction band (CB) edge of acceptor $\left(\mathrm{TiO}_{2}\right)$ and the LUMO of donor (P3HT) (i.e., CB-LUMO energy offset) is $\sim 1.36 \mathrm{eV}$, which enables to break the Coulomb attraction (typically $0.1 \sim 0.5 \mathrm{eV})^{35}$ but not in an efficient way. Gong and his coworkers have discovered that an efficient charge transfer can be observed even if the energy offset is only $0.12 \mathrm{eV}^{17}$. Thus, $\mathrm{MoO}_{3}: \mathrm{Eu}$ nanoparticles were incorporated into $\mathrm{TiO}_{2}$ nanocrystal in the hope of reducing the excess CB-LUMO energy offset. The cyclic voltammetry (CV) characteristics (Supplementary Note 1, Fig. S1, Table S1) show that the incorporation of $\mathrm{MoO}_{3}$ :Eu leads to the changes in the positions of $\mathrm{CB}$ and valence band $(\mathrm{VB})$ of electron acceptor, as displayed in Fig. 1a. After the incorporation of $\mathrm{MoO}_{3}:$ Eu phosphors, the CB-LUMO offset is reduced from 1.36 to $1.01 \mathrm{eV}$, while the VBHOMO offset is changed from 2.27 to $2.03 \mathrm{eV}$. The effect of $\mathrm{Eu}^{3+}$ only on the energy level of $\mathrm{TiO}_{2}$ has been studied by carrying out separate experiments (Fig. S1a). The results show that with the addition of Eu only, the conduction band (i.e., LUMO) energy level does not change much, almost remains unchanged; with the further addition of $\mathrm{MoO}_{3}$, both the $\mathrm{CB}$ and $\mathrm{VB}$ energy levels of acceptor are substantially elevated, indicating that it is $\mathrm{MoO}_{3}$ that plays the dominant role of energy level alignment in this work. However, it should be noted that the main role of Eu ions playing in this work is the down-conversion to widen the absorption range of solar spectrum as to be illustrated in Figure S4. Besides, MottSchottky plots together with UV-vis spectra were also used to separately determine the $\mathrm{CB}$ and $\mathrm{VB}$ positions of acceptors with or without incorporating $\mathrm{MoO}_{3}$ : $\mathrm{Eu}$. The results show that the $\mathrm{CB}, \mathrm{VB}$ and band gap $E_{\mathrm{g}}$ obtained from the $\mathrm{CV}$ characteristics are in reasonable agreement with those determined from the UV-vis and Mott-Schottky plots.

Now one will wonder what influence of the reduction of excess energy offset will exert on the primary dynamics of photoexcited electrons/holes in the $\mathrm{MoO}_{3}: \mathrm{Eu}-\mathrm{TiO}_{2} / \mathrm{P} 3 \mathrm{HT} \mathrm{BHJ}$. Herein, through femtosecond transient absorption spectra and transient photoluminescence of hybrid heterojunctions with selective excitation and probing, we successfully decouple electron and hole dynamics and show evidence of enhancement of hot electron capture by $\mathrm{MoO}_{3}: \mathrm{Eu}$ nanophosphors. In a bid to explore the role of $\mathrm{MoO}_{3}$ : Eu that play in the hot electron transfer, we prepared and characterized two different types of $\mathrm{BHJ}$ solar cells: pure $\mathrm{TiO}_{2} / \mathrm{P} 3 \mathrm{HT}$ and $\mathrm{MoO}_{3}: \mathrm{Eu}-\mathrm{TiO}_{2} /$ P3HT blend films. Scanning electron microscopy (SEM) image of the cross-section of $\mathrm{MoO}_{3}: \mathrm{Eu}-\mathrm{TiO}_{2} / \mathrm{P} 3 \mathrm{HT} \mathrm{BHJ}$ is shown in Fig. 1b. Note that, the porous structure of $\mathrm{TiO}_{2}$ provides channels for P3HT permeating the layer, which can ensure the intimate interface of donoracceptor system. In order to investigate the photoexcited carrier transport in $\mathrm{BHJs}$, time-integrated and transient PL measurements were performed (Supplementary Note 2). As the PL quenching originates from the charge carrier extraction across the interface ${ }^{38,39}$, the intense PL quenching when $\mathrm{MoO}_{3}: \mathrm{Eu}-\mathrm{TiO}_{2}$ is present as acceptor (Fig. S2) suggests a stronger charge transfer in this blended donoracceptor system than bare $\mathrm{TiO}_{2}$. For pure $\mathrm{P} 3 \mathrm{HT}$ film, a single lifetime of 892 ps is obtained by exponentially fitting the transients. While, for $\mathrm{TiO}_{2}$ and $\mathrm{MoO}_{3}: \mathrm{Eu}-\mathrm{TiO}_{2}$ as an electron extraction layer, shortlived components are revealed clearly and dominate the transients. The relative fast component $\left(\tau_{\text {hot-e }} \sim 60-100 \mathrm{ps}\right.$ ) indicates that the hot electron transfer process that quenches the PL intensity becomes more competitive than the photoluminescence of the polymer. However, the time resolution of these measurements ( $\sim 60 \mathrm{ps})$ is not enough to resolve fast quenching. Therefore, femtosecond transient absorption spectroscopy (TAS) with a temporal resolution of $\sim 120$ fs and a high signal to noise ratio (SNR) of $10^{-4}$ was applied to obtain more details on the photoexcited charge carrier dynamics and we have successfully decoupled photoexcited electron and hole dynamics at the interface of donor and acceptor.

It should be noted that since the charge carrier transport from donor to acceptor is central to the device performance of solar cells, therefore in this work, our attention will be paid to the overall hot electron and hole transfer dynamics at the interface of donor P3HT and acceptor $\mathrm{TiO}_{2}$, but no emphasis is not given to distinguish the detailed kinetic information on the excited state species within P3HT, such as the vibrational relaxations from $\mathrm{S}_{1}|\mathrm{~m}\rangle \rightarrow \mathrm{S}_{1}|\mathrm{n}\rangle(\mathrm{m}>$ $\mathrm{n}$ ) because of the almost same time domain of these transitions; Likely, it is also difficult to distinguish the electron transfer from donor to acceptor $\mathrm{S}_{1}|\mathrm{n}\rangle \rightarrow$ the $\mathrm{CB}$ of $\mathrm{TiO}_{2},(\mathrm{n}=0,1,2,3 \ldots)$, as these transitions also are in the same time domain. TA spectra have been widely used to study the charge generation dynamics of different solar cells, however, most of them are mainly related to the charge dynamics at the interface between electron- and hole-transporters $^{40,41}$. Although the TA transient exhibits a complicated temporal profile at the positive time delay, nonetheless the four distinct components are in different time domains, thus allowing one to distinguish them. Typically, the vibrational relaxation time is $\sim 1$ ps while the lifetimes of the hot-electron transfer is on the order of magnitude of several tens of ps. In addition, there exist some difficulties in directly analyzing excited state species such as the vibrational models at the current stage of development, nonetheless it may be overcome in future with the advancement of techniques such as Fourier-transform photocurrents spectroscopy (FTPS) with a laser pump which allows one to examine the excited state species in future works. Finally, it is worth mentioning that excited by $400-\mathrm{nm}(3.1 \mathrm{eV})$ laser pulse, both the acceptor and the donor were promoted to higher excited states. However, herein we focus on the electron transfer from donor to acceptor and the hole transfer from acceptor to donor 


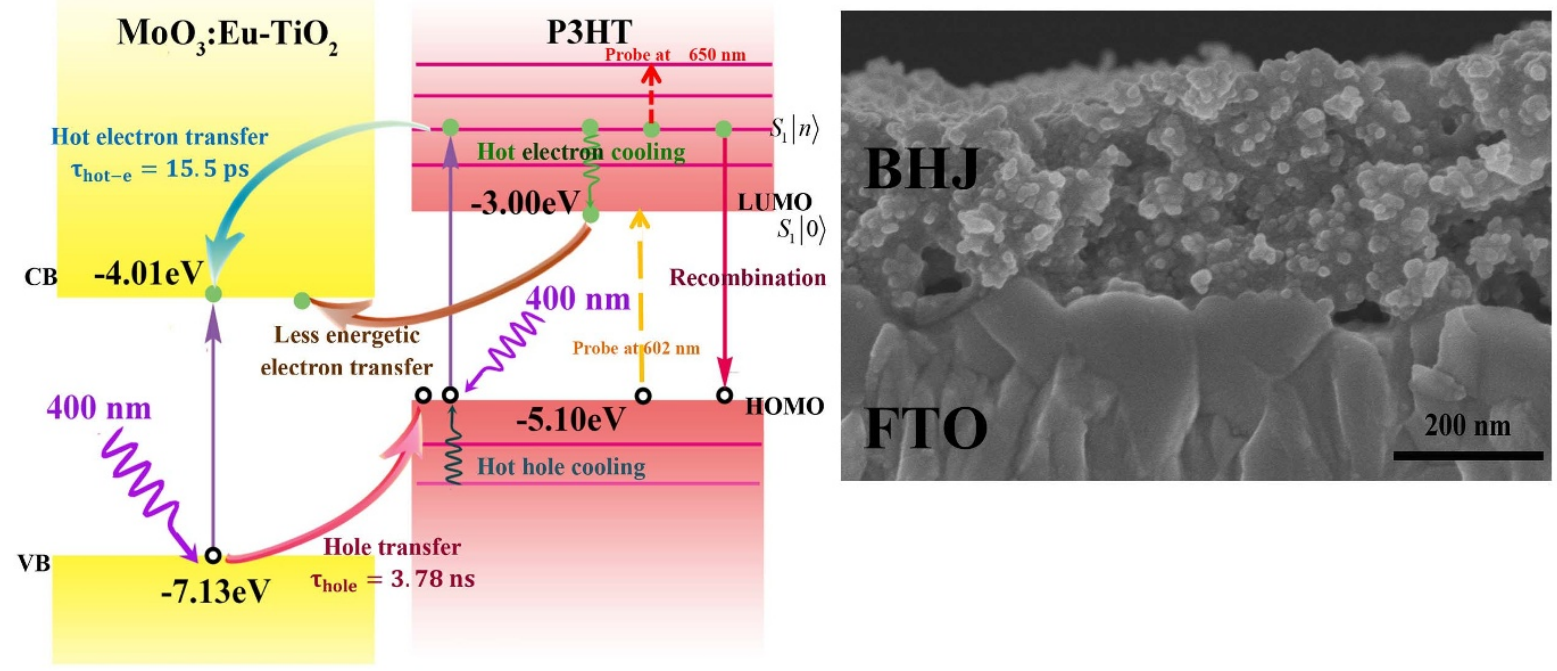

Figure 1 Energy level diagram and structure of $\mathrm{BHJ}$. (a) Schematic diagram of a $\mathrm{BHJ}$ incorporating $\mathrm{MoO}_{3}: \mathrm{Eu}^{-\mathrm{TiO}_{2}}$ layer and the energy level diagram of $\mathrm{BHJ}$. The valence band $(\mathrm{VB})(-7.13 \mathrm{eV})$ and $\mathrm{CB}(-4.01 \mathrm{eV})$ of $\mathrm{MoO}_{3}: \mathrm{Eu}_{-} \mathrm{TiO}_{2}$ are measured from cyclic voltammetry, while the highest occupied molecular orbital (HOMO) $(-5.1 \mathrm{eV})$ and LUMO $(-3.0 \mathrm{eV})$ values are obtained from literature. Optical excitation (up arrows), nonradiative relaxation (curved lines), radiative relaxation (down arrows) and electron/hole transfer times are also displayed. (b) Cross-sectional SEM image of complete $\mathrm{BHJ}$ at high magnification.

because of the positive energy offset ${ }^{42,43}$. In contrast, the contribution of the reverse diffusion of the excited electrons from acceptor $\mathrm{TiO}_{2}$ to donor P3HT almost can be neglected. This is because: apart from the Coulomb binding energy that needs to be overcome, the reverse diffusion process of the excited electrons from the $\mathrm{CB}$ of $\mathrm{TiO}_{2}$ to the LUMO of P3HT needs to overcome the high reverse offset energy as well ${ }^{44}$, therefore the reverse diffusion process can be ignored to a large degree.

The energy band model is used to interpret the optical excitations, subsequent relaxations and photoexcited charge carriers transfer at the interface of acceptor/donor heterojunction in Fig. 1a. Each band, including the associated zero-point level $S_{0}, S_{1}$, which refer to the HOMO and LUMO of P3HT, respectively, and vibronic levels $|n\rangle$, where $\mathrm{n}$ refers to the state formed from certain vibronic electronic configurations. The transitions from the singlet to triplet of $\mathrm{P} 3 \mathrm{HT}$ are not our concerns because of the long intersystem crossing time (hundreds of nanoseconds). At thermoequilibrium, $\mathrm{P} 3 \mathrm{HT}$ resides in the ground state $\mathrm{S}_{0}$. After the high energy photon (with wavelength of $400 \mathrm{~nm}$, i.e., $3.1 \mathrm{eV}$ ) excitation, $\mathrm{P} 3 \mathrm{HT}$ molecules are promoted to a high-lying vibronic energy level of $S_{1}$ state, i.e., the hot electrons are created in $S_{1}|n\rangle$ state and the hot holes are generated in the ground state $S_{1}|0\rangle$. And then, the hot electrons in the highly excited states undergo one of the following processes: a) nonradiative relaxation to lower vibronic energy level (such as $S_{1}|0\rangle$ ) with a decay time of $\tau_{\text {vib1 }}$, typically sub-picosecond ${ }^{45}$; b) geminate recombination with the holes in the ground state, with a lifetime $\left.\tau_{\text {re }}(\sim \text { nanosecond })^{46} ; \mathrm{c}\right)$ injection to the $\mathrm{CB}$ of acceptor with a hot electron transfer time $\tau_{\text {h-e }}(\sim \text { picosecond })^{10}$. Efficient energy conversion in HSCs requires the suppressing the geminate recombination, thus enabling photogenerated electron-hole pair to decouple into long-lived dissociated charges. Yet, in fact, absorption of high-energy photons creates hot electrons that relax quickly ( $\sim 1 \mathrm{ps})$ to the band edge. Energy dissolved from the fast vibronic relaxation will dissipate into heat by emitting phonons (i.e., hot electron cooling). Unfortunately, because of the initial cooling process on the order of hundreds of picoseconds ${ }^{10}$, a substantial amount of solar energy has already been irreversibly lost. Thus, efficient hot carrier capture and injection into the acceptor require shorter transfer time from donor to acceptor, which ensures that the hot electron transport overwhelms the cooling process. We will prove that the favorable energy levels of acceptor can be obtained by incorporating $\mathrm{MoO}_{3}:$ Eu nanophosphors, which reduce both the hot electron and hole transfer time, eventually enhance the performances in HSCs.

The differential absorption spectra of blend films scanning from $580 \mathrm{~nm}$ to $700 \mathrm{~nm}$ with two distinct peaks locating at 602 and $650 \mathrm{~nm}$ are shown in Fig. S3, in agreement with earlier publications ${ }^{41,47}$. Note that the negative absorption bands at $602 \mathrm{~nm}$ are ascribed to the photobleaching $(\mathrm{PB})$ of the ground state absorption that is consistent with the ultraviolet-visible absorption of P3HT (Fig. S4b). In contrast, the positive absorption peak at $\sim 650 \mathrm{~nm}$ is observed immediately after the laser excitation and is ascribed to photoinduced excited states absorption (PA $)^{46}$. For $400-n m$ photoexcitation, it is reasonable to attribute the $650-\mathrm{nm}$ PA band to statefilling effects ${ }^{30,31}$. As observed from Fig. S3a, both the negative and the positive peaks decay quickly from 0 to $30 \mathrm{ps}$, indicating that there exist fast mechanisms influencing PB and PA and this agrees well with the transient PL decays characteristic of obvious PL quenching (Fig. S2b). However, for the longer time scale ( $>30 \mathrm{ps),} \mathrm{PA} \mathrm{peaks}$ decay slowly whereas the PB peaks increase slightly although not so obviously. The different characteristics of PA and PB signals are attributed to complex electronic contributions such as hot electron/hole generation, transfer, and the geminate recombination which are disentangled below (Fig. 2).

The PA signals of the BHJs have been decomposed into four dynamically distinct components that appear common to the inorganic/organic blend films (Fig. 2a). These components include: PA1) a response that is instantaneous on the time scale of the laser pulse and is well represented by a scalar multiple of the laser pulse autocorrelation function that responses instantaneously to the applied laser field; PA2) a fast component ( $<1 \mathrm{ps})$ that accounts for the prominent shoulder in the upper curves according to nonradiative decay by vibronic relaxation $|\mathrm{n}\rangle \rightarrow|0\rangle$ in $\mathrm{P} 3 \mathrm{HT}$ after the excitation of the pump pulses; PA3) an intermediate component with an exponential time constant in the range 1-30 ps, which refers to the hot 
electron transfer to the interface of the heterojunction and contributes to the detected signal; and PA4) a most slowly component, which accounts for the PA decays at probe delays $>30$ ps, representing the contribution of the recombination of the hot electron-hole pairs with a time constant $\tau_{\text {re. }}$. All these decay transients were well fitted with a three exponential function in Supplementary Note 3, and all the time constants were summarized in Table 1. It reveals that the hot electron transfer in $\mathrm{MoO}_{3}: \mathrm{Eu}-\mathrm{TiO}_{2} / \mathrm{P} 3 \mathrm{HT}$ (15.5 ps) becomes much faster than pure $\mathrm{TiO}_{2} / \mathrm{P} 3 \mathrm{HT}$ (30.2 ps) $\mathrm{BHJ}$. Moreover, the efficiency of hot electron transfer can be estimated by using the corresponding fitted amplitude according to the relationship $\mathrm{B}_{1} /$ $\left(\mathrm{A}_{1}+\mathrm{B}_{1}+\mathrm{C}_{1}\right)$, i.e., $12.1 \%$ for $\mathrm{TiO}_{2} / \mathrm{P} 3 \mathrm{HT}$ and $13.8 \%$ for $\mathrm{MoO}_{3}: \mathrm{Eu}-\mathrm{TiO}_{2} / \mathrm{P} 3 \mathrm{HT}$. After the incorporation of $\mathrm{MoO}_{3}: \mathrm{Eu}$, the CB-LUMO offset has decreased by $0.35 \mathrm{eV}$, i.e., from 1.36 down to $1.01 \mathrm{eV}$ (Table S1). Detailed comparasive studies of the TAS measurements of neat P3HT film and $\mathrm{MoO}_{3}: \mathrm{Eu}_{-} \mathrm{TiO}_{2} / \mathrm{P} 3 \mathrm{HT}$ (Fig. S3a and $\mathrm{S} 3 \mathrm{~b}$ ) indicate that in this report, the variation of electron population in $S_{1}$ state should dominate the contribution to PA transients: from 1 to 30 ps, the PA band decreases $64 \%$ and $23 \%$, for $\mathrm{MoO}_{3}$ :Eu$\mathrm{TiO}_{2} / \mathrm{P} 3 \mathrm{HT}$ and neat $\mathrm{P} 3 \mathrm{HT}$, respectively. This remarkable difference suggests that there exists hot electron transfer from $\mathrm{P} 3 \mathrm{HT}$ to $\mathrm{MoO}_{3}: \mathrm{Eu}-\mathrm{TiO}_{2}$ within $1 \sim 30 \mathrm{ps}$, thus resulting in the quenching of PA signal. Despite the reduction of the energy level offset, it is still greater than the Coulomb binding energy (typically $0.1 \sim 0.5 \mathrm{eV}$ ), enabling the initial electron transfer step to be energetically down$\mathrm{hill}^{35}$. The reduction of the excess energy offset enables the energetic electron transfer to the interface with less energy loss, and has resulted in one remarkable improvement in PCE for solar cells ${ }^{15-17}$, which supports the conclusion that the observed hot-electron transfer improvement in this hybrid $\mathrm{BHJ}$ stems from energy level regulation. Note that, since the cooling time of hot electron is on the order of several hundreds of picoseconds and there exists competition between the hot electron transfer and cooling thereby. But after the incorporating $\mathrm{MoO}_{3}: \mathrm{Eu}$ nanophosphors, the hot electron transfer becomes more competitive.

From the long timescale of the decay curves, we found that the recombination time of electron-hole pairs were estimated to be $14.0 \mathrm{~ns}\left(\mathrm{TiO}_{2}\right.$ as acceptor) and $3.4 \mathrm{~ns}\left(\mathrm{MoO}_{3}: \mathrm{Eu}-\mathrm{TiO}_{2}\right.$ as acceptor), respectively. This indicates that after the incorporation of $\mathrm{MoO}_{3}: \mathrm{Eu}$, the electrons in high excited states decay faster than that of pure $\mathrm{TiO}_{2}$, implying that there are more electrons departing from the $\mathrm{S}_{1}|\mathrm{n}\rangle$ state. Nevertheless, from the transient absorption dynamics of $\mathrm{PB}$ in Fig. 2b, there is no decay of the hole in the VB of P3HT

\section{a}

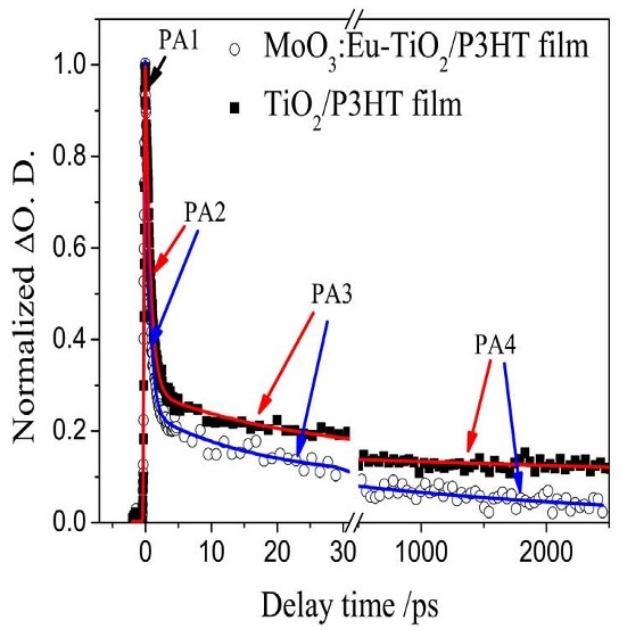

on the long time scale (30 ps to $2.5 \mathrm{~ns}$ ) either in $\mathrm{TiO}_{2}$ or $\mathrm{MoO}_{3}: \mathrm{Eu}-$ $\mathrm{TiO}_{2}$ as acceptor present. If all the electrons that depart from the $\mathrm{S}_{1}$ state relax to the ground state $S_{0}$, the hole population decay should resemble the PA signal. On the basis of conservation of particle number, the discrepancy of the electron-hole recombination time and the hole decay time can be attributed to the 'less energetic' electron transfer from donor to acceptor. In other words, there exists another pathway for the electron relaxation. Those hot electrons in a vibronic energy level of $S_{1}|n\rangle$ state first relax to lower vibronic energy level $S_{1}|0\rangle$, and then may have enough time to transfer from donor to acceptor because of the long lifetime of geminate recombination $(\sim \mathrm{ns})$. Note that the recombination time is quenching from 14.0 to $3.4 \mathrm{~ns}$, as a result this electron transfer time can be estimated on the order of several ns. As the initial cooling process, a lot of energy dissipates by emission of phonons, and then those hot electrons develop into 'less energetic' electrons. The contribution of the less energetic electron transfer would be concurrent with the recombination process. Therefore, the reduction of the electron-hole recombination time reflects that large quantities of less energetic electrons transfer to the interface. In a short summary, $\mathrm{MoO}_{3}$ : $\mathrm{Eu}$ not only reduces the hot-electron transfer time to the interface, but also improves the 'less energetic' electron transfer, and it benefits the charge separation. This indicates that through optimizing the energy level configuration, both the energetic hot electrons and the less energetic' electrons can be extracted more efficiently.

As mentioned above, the TAS measurements for $\mathrm{TiO}_{2} / \mathrm{P} 3 \mathrm{HT}$ and $\mathrm{MoO}_{3}: \mathrm{Eu}-\mathrm{TiO}_{2} / \mathrm{P} 3 \mathrm{HT}$ films at a probe wavelength of $602 \mathrm{~nm}(\mathrm{~PB})$, which monitors the population of holes in the ground state of $\mathrm{P} 3 \mathrm{HT}$, are shown in Fig. 2b. Excited by $400-\mathrm{nm}(3.1 \mathrm{eV})$ laser pulse, both the acceptor and the donor were promoted to higher excited states. A large number of holes were formed in the ground state instantaneously. The holes in the ground state of $\mathrm{TiO}_{2}$ will not decay rapidly due to the long recombination time $(\sim \mathrm{ns})$. Therefore, the holes in acceptor have enough time to break the Coulomb attraction and cross to the valence bands (HOMO) of P3HT. When probed at $602 \mathrm{~nm}$, the probe beam experienced the holes decay with three contributions: PB1) an instantaneous response by a scalar multiple of the laser pulse autocorrelation function; PB2) hot hole cooling by vibrational relaxation; PB3) a combined contribution for hole transfer from acceptor to $\mathrm{P} 3 \mathrm{HT}$ and geminate recombination with the electrons in excited state $S_{1}$. Potentially, these hot-hole energies could be efficiently extracted before the hot holes cool down by vibrational relaxation through optimizing the energy level formation. However,

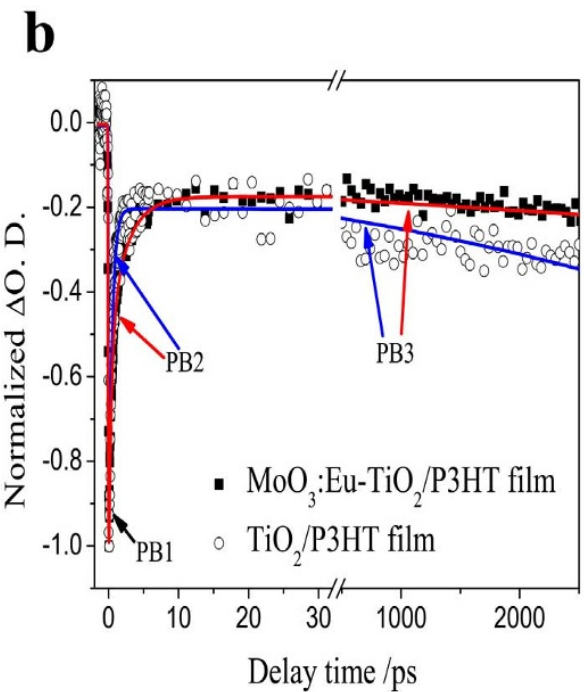

Figure $2 \mid$ Photoexcited carriers dynamics of BHJs. Normalized femtosecond transient absorption decays of $\mathrm{MoO}_{3}: \mathrm{Eu}_{-} \mathrm{TiO}_{2} / \mathrm{P} 3 \mathrm{HT}(\mathrm{open}$ circle) and $\mathrm{TiO}_{2} / \mathrm{P} 3 \mathrm{HT}$ (square) films excited at $400 \mathrm{~nm}$ with irradiance of $17 \mu \mathrm{J} \cdot \mathrm{cm}^{-2}$ : (a) probed at $650 \mathrm{~nm}$; (b) probed at $602 \mathrm{~nm}$. Solid lines are theoretical fits. 
Table 1 | Lifetimes and the amplitudes fit from TAS

\begin{tabular}{|c|c|c|c|c|c|c|}
\hline Lifetime $(\tau)$ (amplitude) & $\tau_{\text {vibl } 1} / \mathrm{ps}\left(\mathrm{A}_{1}\right)$ & $\tau_{\text {hotee }} / \mathrm{ps}\left(B_{1}\right)$ & $\tau_{\mathrm{re}} / \mathrm{ns}\left(\mathrm{C}_{1}\right)$ & $\tau_{\text {vib2 }} / \mathrm{ps}\left(\mathrm{A}_{2}\right)$ & $\tau_{\text {complex }} / \mathrm{ns}\left(\mathrm{B}_{2}\right)$ & $\tau_{\mathrm{h}} / \mathrm{ns}$ \\
\hline $\mathrm{MoO}_{3}: \mathrm{Eu}^{-T i O}{ }_{2} / \mathrm{P} 3 \mathrm{HT}$ & $\begin{array}{c}0.68 \pm 0.01 \\
(0.90)\end{array}$ & $\begin{array}{c}15.5 \pm 1.2 \\
(0.16)\end{array}$ & $\begin{array}{c}3.4 \pm 0.2 \\
(0.10)\end{array}$ & $\begin{array}{c}0.62 \pm 0.04 \\
(-0.85)\end{array}$ & $\begin{array}{c}4.2 \pm 0.3 \\
(-0.22)\end{array}$ & $3.78 \pm 0.24$ \\
\hline $\mathrm{TiO}_{2} / \mathrm{P} 3 \mathrm{HT}$ & $\begin{array}{c}0.74 \pm 0.01 \\
(0.95)\end{array}$ & $\begin{array}{c}30.2 \pm 1.0 \\
(0.15)\end{array}$ & $\begin{array}{c}14.0 \pm 1.5 \\
(0.14)\end{array}$ & $\begin{array}{c}0.80 \pm 0.04 \\
(-0.81)\end{array}$ & $\begin{array}{c}8.5 \pm 1.0 \\
(-0.19)\end{array}$ & $6.92 \pm 1.08$ \\
\hline
\end{tabular}

both the cooling of hot holes and the recombination with electrons will reduce the population of holes. Although there exists competition between the generation of new holes and the quenching, nevertheless, from the long time scale, i.e., 30 ps to $2.5 \mathrm{~ns}$ in Fig. $2 \mathrm{~b}$, the recovery of $\mathrm{PB}$ decay is hardly observed either in $\mathrm{TiO}_{2} / \mathrm{P} 3 \mathrm{HT}$ or $\mathrm{MoO}_{3}: \mathrm{Eu}-\mathrm{TiO}_{2} / \mathrm{P} 3 \mathrm{HT}$ blend films, despite the recombination of the electron-hole pairs. This indicates that the PB decay is dominated by the generation of new holes that originate from the holes transfer from acceptor to donor at long time scale. From fitting the normalized absorption PB decay dynamics with the double expotentially equation (Supplementary Note 3), the complex decay time decreases from $8.5 \pm 1.0$ to $4.2 \pm 0.3 \mathrm{~ns}$. Assuming that fluorescence decay time of P3HT kept unchanged, i.e., $\tau_{\text {flu }}=38 \pm 12 \mathrm{~ns}$ as obtained from fits to time-resolved PL decay transients of Figure S2, the hole transfer time $\tau_{\mathrm{h}}$ should alter from 6.92 to $3.78 \mathrm{~ns}$ according to the relation $1 / \tau_{\text {complex }}=1 / \tau_{\mathrm{h}}-1 / \tau_{\mathrm{flu}}{ }^{48}$ after the incorporation of $\mathrm{MoO}_{3}: \mathrm{Eu}$. However, the PB decays have contributions from both geminate recombination and hole transfer, it is difficult to estimate the detailed hole transfer efficiency at this stage. Note that after incorporating $\mathrm{MoO}_{3}$ : Eu nanophosphors, VB-HOMO offset was narrowed (Table S1) by $0.24 \mathrm{eV}$. The narrowing of excess energy offset induces the hole transfer to the interface much faster with less energy loss. Shorter transfer time benefits the hole extraction, which in turn improves hole transport in $\mathrm{BHJ}$.

It is worth mentioning that the order of magnitude of lifetimes for electrons (several tens of ps) and holes ( ns) seems quite different. In this work, it should be noted that the electrons were classified into two types: the hot electrons and 'less energetic' electrons. Although the transfer time of the 'less energetic' electron cannot be quantified at present, nonetheless the transfer time can be estimated on the timescale of $\sim \mathrm{ns}$ and this agrees well with other reported results ${ }^{40}$. However, our attention herein is paid to the hot electrons, whose transfer lifetime is on the order of several tens of ps that is intermediate between those of the vibrational relaxations (within $\sim 1 \mathrm{ps}$ ) and 'less energetic' electrons $(\sim \mathrm{ns})$. This result is also in agreement with the other reported works ${ }^{45,49}$.

Characterizations of nanophosphors and photovoltaic properties. The X-ray diffraction pattern (XRD) pattern of europium ion decorated molybdenum trioxide phosphor, i.e., $\mathrm{MoO}_{3}: \mathrm{Eu}$ is shown in Fig. 3a. It reveals that all the diffraction peaks can be readily indexed as those of hexagonal molybdenum trioxide $\left(\mathrm{MoO}_{3}\right)$ and monoclinic europium molybdenum oxide $\left(\mathrm{Eu}_{2} \mathrm{Mo}_{2} \mathrm{O}_{6}\right)$ that are consistent with the standard patterns JCPDS 00-021-0569, JCPDS $00-024-0417$ respectively. In detail, the peaks at $21.20^{\circ}, 24.50^{\circ}, 28.20^{\circ}$ and $28.76^{\circ}$ obtained from XRD pattern are in agreement with those of $\mathrm{Eu}_{2} \mathrm{Mo}_{2} \mathrm{O}_{6}$ according to JCPDS 00-024-0417, which correspond to the [2 11$],[130],[\overline{3} 21]$ and [321] planes of the hexagonal phase, respectively. Likewise, the characteristc peaks at $19.45^{\circ}, 25.80^{\circ}$, $31.02^{\circ}$ and $45.47^{\circ}$ obtained from XRD pattern are in excellent with those of $\mathrm{MoO}_{3}$ according to JCPDS 00-021-0569, which can be assigned to the [200], [210], [204] and [410] planes of the monoclinic phase, respectively. It can be clearly seen from SEM micrographs in Fig. $3 \mathrm{~b}$ that $\mathrm{MoO}_{3}: \mathrm{Eu}$ nanophosphors are well dispersed within $\mathrm{TiO}_{2}$ nanocrystal, although the contents of $\mathrm{MoO}_{3}$ :Eu are low. $\mathrm{MoO}_{3}: \mathrm{Eu}$ appears as a loose agglomeration of nanoparticles with a size of about $50 \sim 80 \mathrm{~nm}$, and the surface of $\mathrm{MoO}_{3}: \mathrm{Eu}-\mathrm{TiO}_{2}$ seems rough and porous. As observed from Figure 3b, the surface of the prepared $\mathrm{TiO}_{2}$ acceptor layers clearly exhibits a porous structure, which favors the physical adsorption of $\mathrm{P} 3 \mathrm{HT}$ molecules by trapping the solution in the microporomerics because of the intermolecular attractive forces ${ }^{50-52}$. Fig. $3 c$ shows the transmission electron microscopy (TEM) image of the prepared powder and a loose agglomeration of nanoparticles with a size of about $50 \sim$ $80 \mathrm{~nm}$ can be obaerved. As highlighted in the inset, most of $\mathrm{MoO}_{3}$ : Eu particles are in the order of about $70 \mathrm{~nm}$ in diameter, which is cosistent with SEM results. Fig. 3d reveals the high resolution TEM (HR-TEM) images and the corresponding selected area electron diffraction (SAED) patterns of $\mathrm{MoO}_{3}: \mathrm{Eu}$ nanophosphors. The estimated distance spacing of $\mathrm{d}_{1}=0.32 \mathrm{~nm}, \mathrm{~d}_{2}=$ $0.31 \mathrm{~nm}$ are in agreement with those from the standard XRD pattern JCPDS 00-024-0417, i.e., $d_{1}=0.31 \mathrm{~nm}, d_{2}=0.30 \mathrm{~nm}$, which lend further support to the above XRD analysis. Finally, it is worth mentioning that the doping amount of $\mathrm{MoO}_{3}$ : Eu relative to the total amount of $\mathrm{MoO}_{3}: \mathrm{Eu}$ and $\mathrm{TiO}_{2}$ is limited. Therefore, the interactions between $\mathrm{P} 3 \mathrm{HT}$ and $\mathrm{TiO}_{2}$ with or without incorporating $\mathrm{MoO}_{3}$ :Eu dopants almost remain unchanged. So far many efforts have been devoted to the interface modification by introducing small molecule species to improve the photovoltaic performances using hydrogen bonding, etc ${ }^{53,54}$. The results of these works indeed show that with much stronger interaction between $\mathrm{P} 3 \mathrm{HT}$ and $\mathrm{TiO}_{2}$ can assist in charge separation efficiency and provide highly efficient transport pathways, thus improving open-circuit voltage, FF or photocurrent. However, this work is initially motivated by exploring the potential powerful role of $\mathrm{MoO}_{3}$ :Eu playing in inorganic/organic HSCs, without paying attention to the further fine design of the devices, which should be a promising engineering rule that needs to be considered in future.

The $J-V$ characteristics of the HSCs under a simulated solar light irradiation of $100 \mathrm{~mW} \cdot \mathrm{cm}^{-2}$ are shown in Fig. 4, and summarized in Table 2. It reveals that the $\mathrm{MoO}_{3}: \mathrm{Eu}-\mathrm{TiO}_{2} / \mathrm{P} 3 \mathrm{HT}$ HSC exhibits better device performances than the $\mathrm{TiO}_{2} / \mathrm{P} 3 \mathrm{HT}$ HSC, especially in terms of current density. A notable conversion efficiency of $3.21 \%$ is therefore attained in the $\mathrm{MoO}_{3}: \mathrm{Eu}-\mathrm{TiO}_{2} / \mathrm{P} 3 \mathrm{HT}$ solar cell as compared to the $\mathrm{TiO}_{2} / \mathrm{P} 3 \mathrm{HT}$ solar cell $(1.98 \%)$. The current density $J_{S C}$ is governed by the device quantum efficiency, which depends on the light-absorption capacity of the semiconductor, the efficiency of photoexcited carrier transfer and charge collection ${ }^{35}$. In $\mathrm{MoO}_{3}: \mathrm{Eu}-$ $\mathrm{TiO}_{2} / \mathrm{P} 3 \mathrm{HT}$ based HSCs, on one hand, $\mathrm{MoO}_{3}$ :Eu nanophosphors reduce excess CB-LUMO energy offset, and accelerate the hot carrier transfer. On the other hand, $\mathrm{MoO}_{3}:$ Eu nanophosphors, acting as a down-conversion luminescence medium, transfers ultraviolet light to visible light (Supplementary Note 4, Fig. S4), and increases incident harvest $\mathrm{t}^{22-24}$. Additionally, the energy levels of acceptor are controlled by $\mathrm{MoO}_{3}$ : $\mathrm{Eu}$ while the energy levels of donor remain unchanged, which is prone to give rise to a higher $V_{\mathrm{OC}}$ according to the following relationship ${ }^{33,44}$ :

$$
V_{O C}=\left|\mathrm{HOMO}_{\mathrm{D}}\right|-\left|\mathrm{LUMO}_{\mathrm{A}}\right|-\frac{k T}{q} \ln \left(\frac{N_{e f f}^{2}}{n p}\right)
$$

where $\mathrm{HOMO}_{\mathrm{D}}$ is the highest occupied molecular orbital (HOMO) of the donor, $\mathrm{LUMO}_{\mathrm{A}}$ is the lowest unoccupied molecular orbital (LUMO) of the acceptor, $k$ is the Boltzmann constant, $q$ is the ele- 


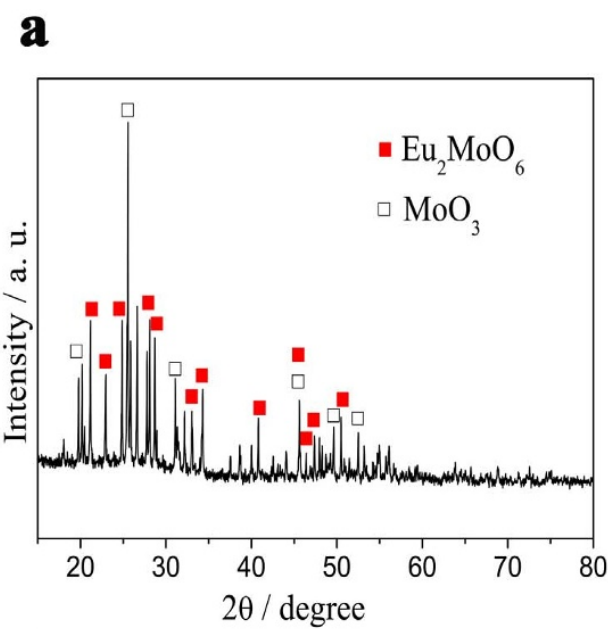

b
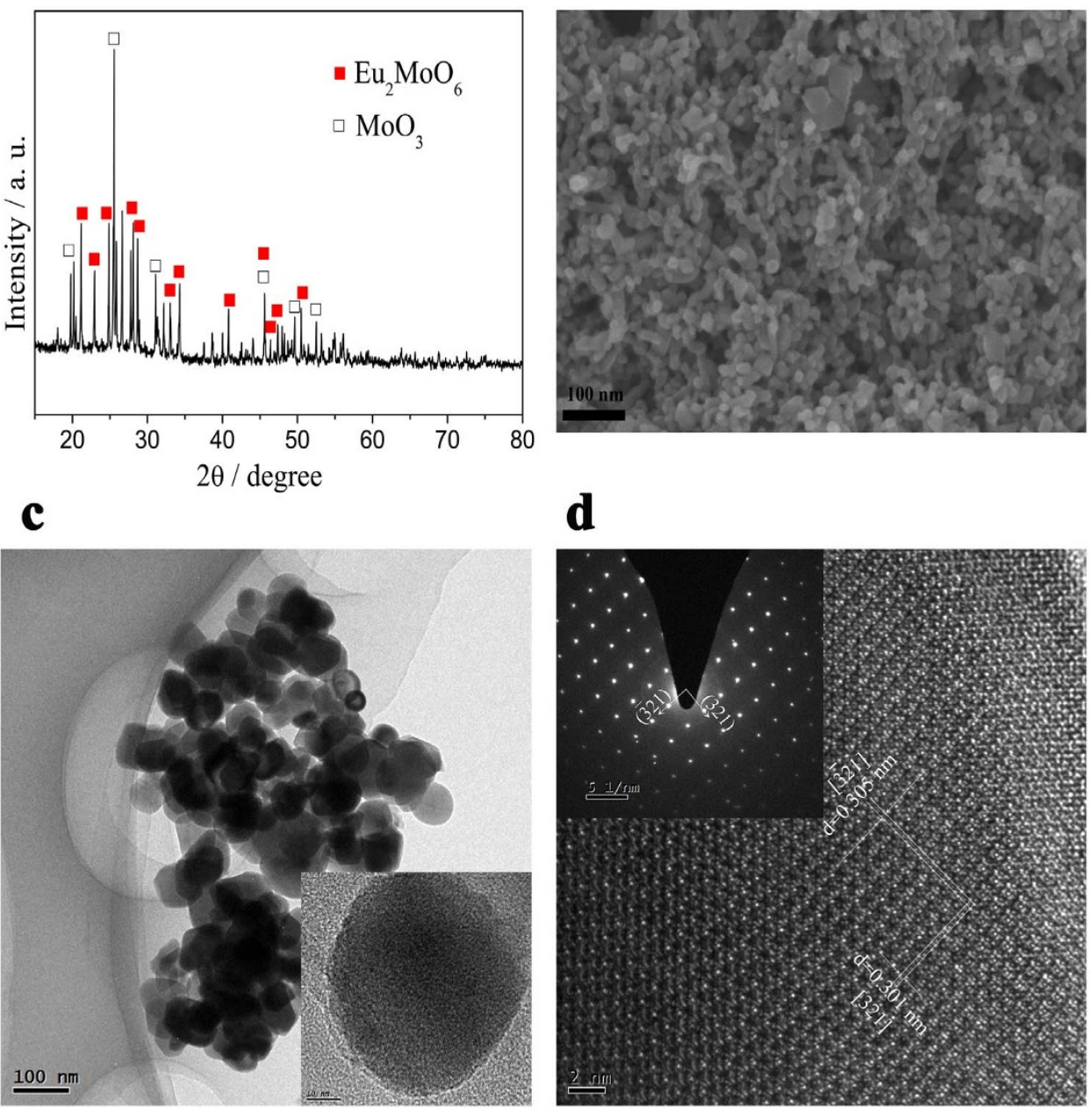

Figure 3 Structure characteristics. (a) XRD pattern of $\mathrm{MoO}_{3}$ :Eu powder; (b) $\mathrm{SEM}$ image of $\mathrm{MoO}_{3}: \mathrm{Eu}_{-} \mathrm{TiO}_{2}$ film; (c) TEM image of MoO :Eu powder, the insert highlights TEM image at high magnification; (d) HR-TEM image of $\mathrm{MoO}_{3}$ :Eu nanophosphors, the inset highlights the SAED pattern.

mentary charge, $\mathrm{T}$ is temperature, $N_{\text {eff }}$ is the effective density of state, and $n, p$ are the concentrations of electrons and holes, respectively. This relationship demonstrates that the $V_{\mathrm{oc}}$ is determined by the energy offset between $\mathrm{HOMO}_{\mathrm{D}}$ and $\mathrm{LUMO}_{\mathrm{A}}$. Note that the CB-

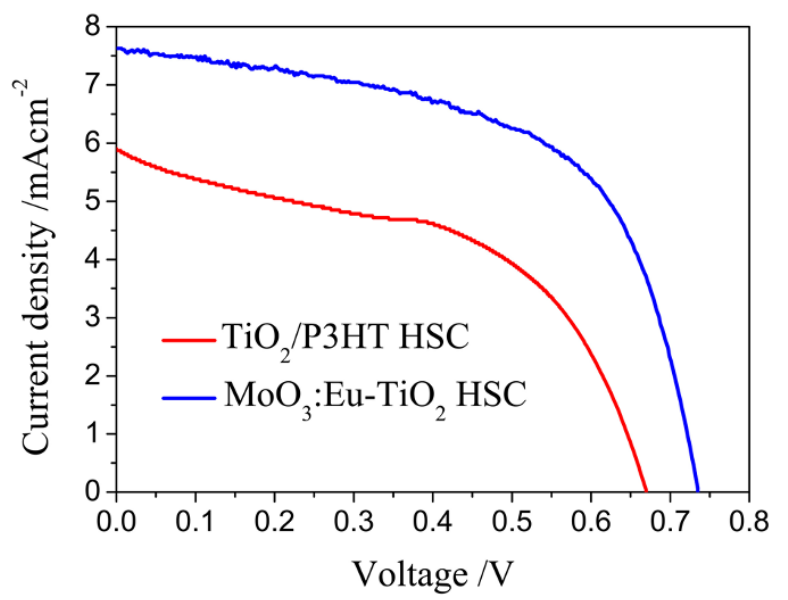

Figure $4 \mid$ Hybrid solar cell photovoltaic performance. Photocurrentvoltage $(\mathrm{J}-\mathrm{V})$ characteristics curves of $\mathrm{HSCs}$ from pure $\mathrm{TiO}_{2} / \mathrm{P} 3 \mathrm{HT}$ and $\mathrm{MoO}_{3}: \mathrm{Eu}-\mathrm{TiO}_{2} / \mathrm{P} 3 \mathrm{HT}$ BHJ.
HOMO offset of $\mathrm{MoO}_{3}: \mathrm{Eu}-\mathrm{TiO}_{2} / \mathrm{P} 3 \mathrm{HT}$ is $1.09 \mathrm{eV}$, which is greater than pure $\mathrm{TiO}_{2} / \mathrm{P} 3 \mathrm{HT}(0.74 \mathrm{eV})$.

\section{Discussion}

We have studied the effect of $\mathrm{MoO}_{3}: \mathrm{Eu}$ on the $\mathrm{CB}$ and $\mathrm{VB}$ energy edges of acceptor and especially the role of hot electron transfer at the interface of acceptor and donor in hybrid BHJs, and demonstrated the first attempt on enhancing the hot electron transport efficiency by means of the incorporation of $\mathrm{MoO}_{3}$ : Eu to control the energy level of acceptor. A key feature of this work is the use of a series of spectroscopies with selective excitation and probe to unveil the dynamics of electron/hole transfer. CVs experiments show that the VB as well as $\mathrm{CB}$ of acceptor have been tuned by $\mathrm{MoO}_{3}$ :Eu nanophosphors. TAS analysis indicates that the reduction of excess CB-LUMO offset shortens hot electron transfer time and charge collection can be efficiently promoted. The incorporation of $\mathrm{MoO}_{3}$ : Eu leads to an

Table 2 | Photovoltaic parameters of the HSCs based on different $\mathrm{BHJs}$

\begin{tabular}{|c|c|c|c|c|}
\hline $\mathrm{BHJ}$ & $V_{o c}[V]$ & $J_{\mathrm{sc}}\left[\mathrm{mA} \cdot \mathrm{cm}^{-2}\right]$ & $F F$ & $\eta^{\text {a) }}[\%]$ \\
\hline $\mathrm{MoO}_{3}: \mathrm{Eu} \mathrm{TiO}_{2} / \mathrm{P} 3 \mathrm{HT}$ & 0.735 & 7.53 & 0.58 & 3.21 \\
\hline $\mathrm{TiO}_{2} / \mathrm{P} 3 \mathrm{HT}$ & 0.670 & 5.91 & 0.50 & 1.98 \\
\hline
\end{tabular}


elevation of the $\mathrm{CB}$ of acceptor by $0.35 \mathrm{eV}$ (i.e., from -4.36 to $-4.01 \mathrm{eV}$ ) and correspondingly the hot electron transfer time from donor to acceptor shortens by $48 \%$ (i.e., from 30.2 to 15.5 ps). Meanwhile, the VB of acceptor has been elevated by $0.24 \mathrm{eV}$ from -7.37 to $-7.13 \mathrm{eV}$ and the hole transfer lifetime, is predicted to decrease from 6.96 to $3.78 \mathrm{~ns}$. Moreover, $\mathrm{MoO}_{3}: \mathrm{Eu}$ also improves the efficiency of 'less energetic' electron transfer although not explicitly quantified, but obviously observed.

These results suggest that further improvements in hot electron/ hole capture should be possible by achieving an even greater reduction of excess CB-LUMO or VB-HOMO offset, and gaining balanced injection of hot electrons and holes after incorporating more suitable materials. Given the low PCE even in our devices, we expect that with further construction utilizing more reactive ions, the performance of these novel efficient hot carrier HSCs can be enhanced considerably, making them competitive with well-established Si-based solar cells.

\section{Methods}

Characterizations. The X-ray powder diffraction (XRD) data were collected in a scan mode with a scanning speed of $5^{\circ} \cdot \mathrm{min}^{-1}$ and $2 \theta$ in the range between 10 and $80^{\circ}$ using a Rigaku MiniFlex II X-ray diffractometer using $\mathrm{Cu} K \alpha$ radiation $(\lambda=0.154 \mathrm{~nm})$ at a power of $30 \mathrm{kV}$ and $40 \mathrm{~mA}$. The morphologies of the $\mathrm{MoO}_{3}: \mathrm{Eu}$ nanophosphors and the cross-section of $\mathrm{BHJ}$ were characterized by using a field emission scanning electron microscope (FE-SEM, Hitachi S4800). The microstructure of $\mathrm{MoO}_{3}: \mathrm{Eu}$ nanophosphors was further analyzed by using a transmission electron microscope (TEM) (JEM-2010, JEOL Ltd.) working at $200 \mathrm{kV}$, and high-resolution TEM (HR TEM) and selected area electron diffraction (SAED) were also carried out. Samples for TEM and HR-TEM were prepared by ultrasonically dispersing the samples in absolute ethanol, placing a small volume of this suspension on carbon-enhanced copper grids, and drying in air. The cyclic voltammetry (CV) results were obtained using a BAS $100 \mathrm{~B}$ instrument at room temperature and a scan rate of $50 \mathrm{mV} \cdot \mathrm{s}^{-1}$ with $0.1 \mathrm{M} \mathrm{TBAPF}_{6}$ in acetonitrile as the supporting electrolyte, a platinized platinum $\left(1.0 \mathrm{~cm}^{2}\right)$ as the counter electrodes, and $\mathrm{Ag} / \mathrm{Ag}^{+}$electrode as the reference electrode; the values are expressed in potentials versus $\mathrm{F}_{c} / \mathrm{F}_{\mathrm{c}}{ }^{+}$. Mott-Schottky measurements were done at the frequency of $1 \mathrm{kHz}$ in the aqueous solution of $0.05 \mathrm{M} \mathrm{Na}_{2} \mathrm{SO}_{4}$ using a BAS 100B instrument and $\mathrm{Ag} / \mathrm{Ag}+$ electrode as the reference electrode. The photoluminescence spectrum was measured by using a spectrophotometer (FLS920, Edinburgh), in which a xenon lamp and a photomultiplier tube (R955, Hamamatsu) were used as excitation source and fluorescence detector, respectively. The photocurrent-voltage $(J-V)$ curves of the assembled HSCs were recorded on an Electrochemical Workstation (Xe Lamp Oriel $\mathrm{Sol}_{3} \mathrm{~A}^{\mathrm{TM}}$ Class AAA Solar Simulators 94023A,USA) under irradiation of a simulated solar light from a $100 \mathrm{~W}$ xenon arc lamp in ambient atmosphere.

Transient photoluminescence experiments were measured on a spectrometer (Bruker Optics 250IS/SM) with intensified charge coupled device detector (Andor, IStar740). The samples were excited by $120 \mathrm{fs}$ laser pulses at $400 \mathrm{~nm}$ with a repetition rate of $10 \mathrm{~Hz}$. The time resolution of this experiment was determined to be $\sim 60 \mathrm{ps}$. TAS measurements of the BHJs were performed by the mode-locked Ti:sapphire laser (Coherent Mira 900) in combination with a regenerative amplifier (Coherent LegendF). The ultrafast light source with a temporal resolution of $\sim 120$ fs was generated by a mode-locked titanium-sapphire laser operating at $800 \mathrm{~nm}$. An optical parametric amplifier (OPA-800CF-1, Spectra Physics) provided ultra-short laser pulses at desired wavelengths ( $\sim 120 \mathrm{fs}$, full width at half maximum). A continuum white light generated from a sapphire plate was directed into the excited sample and detected by a charge coupled device (CCD) detector. Ultra-short laser pulses at $400 \mathrm{~nm}$ were employed as the pump light for the sample excitation and the probe light for the absorption measurement. Transient absorption at various delay times could be measured by controlling the arrival time of each laser pulse at the sample. The laser system was operated at a repetition rate of $10 \mathrm{~Hz}$, and the corresponding time interval of each pulse is $0.1 \mathrm{~s}$. Since the time interval was long enough for the sample to reach fully thermodynamic equilibrium before the next pulse arrived, thus the already fully relaxed sample can be excited by each pulse. Each data was obtained by averaging 100 individual measurements to improve the signal-to-noise ratio, and the typical detection sensitivity of the difference absorption $(\Delta \mathrm{OD})$ was better than $10^{-4}$.

Materials. Chemical reagents including tetrabutyl titanate, polyethylene glycol (molecular weight of 20000), nitric acid, P25 (Degussa), OP emulsifying agent (Triton $\mathrm{X}-100$ ), europium nitrate hexahydrate, methylbenzene, isopropanol, acetonitrile, ammonium molybdate tetrahydrate are analytic purity and purchased from SigmaAldrich, Hongkong, China. Conjugated polymer P3HT and poly (3, 4ethylenedioxylenethiophene)-polystylene sulfonic acid (PEDOT:PSS) were provided by Aldrich. Fluorine-doped tin oxide glass (FTO, sheet resistance $8 \Omega \cdot \mathrm{cm}^{-2}$ ) was purchased from Hartford Glass Co., USA.

Preparation of $\mathrm{MoO}_{3}$ :Eu nanoparticles. $\mathrm{MoO}_{3}$ :Eu nanophosphors were prepared by a modification of hydrothermal method as reported before ${ }^{22}$. Firstly, europium nitrate hexahydrate $(0.500 \mathrm{mmol})$ was thoroughly dissolved in de-ionized water $(50 \mathrm{~mL})$.
Then, quickly transferred into a Teflon-lined stainless-steel autoclave, followed by adding ammonium molybdate tetrahydrate $(0.1 \mathrm{~mol})$ into the autoclave under stirring. Afterwards, appropriate de-ionized water was added until the filled degree reached $80 \%$ of the total container volume. Then $\mathrm{pH}$ value of the mixed solution was adjusted to 4 using nitric acid. The obtained solution was hydrothermally treated at $200^{\circ} \mathrm{C}$ for $12 \mathrm{hr}$. After being naturally cooled to room temperature, the obtained product was centrifuged, washed until the $\mathrm{pH}$ value of the system reached 7 , and then dried in air at ambient temperature, followed by sintering in air at $850^{\circ} \mathrm{C}$ for $30 \mathrm{~min}$.

Synthesis of $\mathrm{MoO}_{3}: \mathrm{Eu}-\mathrm{TiO}_{2}$ acceptor colloid. The acceptor colloid was prepared by the following procedure ${ }^{55,56}$. Tetrabutyl titanate $(10 \mathrm{~mL})$ was added to distilled water $(100 \mathrm{~mL})$ under stirring, followed by a white precipitate immediately. The precipitate was filtered, washed with distilled water, and then transferred to a mixed solution $(150 \mathrm{~mL})$ containing nitric acid $(1 \mathrm{~mL})$ and acetic acid $(10 \mathrm{~mL})$ at $80^{\circ} \mathrm{C}$. Under vigorous stirring a light blue $\mathrm{TiO}_{2}$ precursor was formed, followed by an ultrasonic stirring for $30 \mathrm{~min}$. Finally, the mixture was hydrothermally treated in an autoclave at $200^{\circ} \mathrm{C}$ for $24 \mathrm{hr}$ to form a colloid of $\mathrm{TiO}_{2}$. Subsequently, the P25 (0.075 g), OP emulsifying agent $(1 \mathrm{~mL})$ and $\mathrm{MoO}_{3}$ :Eu nanophonsors $(0.150 \mathrm{~g})$ were dispersed into the $\mathrm{TiO}_{2}$ colloid by ultrasonically vibrating for $90 \mathrm{~min}$ and hydrothermally treating at $200^{\circ} \mathrm{C}$ for $12 \mathrm{hr}$ to form a white colloid. At last, the resultant slurry was concentrated to $1 / 5$ of its original volume by a thermal evaporation, and PEG-20000 (0.5 g) and a few drops of the Triton X-100 emulsification reagent were added and an even and stable $\mathrm{TiO}_{2}$ colloid was produced.

Fabrication of $\mathrm{HSC}$ devices. A layer of nanocrystalline $\mathrm{MoO}_{3}: \mathrm{Eu}-\mathrm{TiO}_{2}$ acceptor film with a thickness of about $200 \mathrm{~nm}$ was prepared by coating the $\mathrm{TiO}_{2}$ colloid on Fluorine-doped tin oxide (FTO) glass using spin-coating technique, followed by sintering in air at $450^{\circ} \mathrm{C}$ for $30 \mathrm{~min}$. Then the acceptor film was soaked in a $0.15 \mathrm{mmol} \cdot \mathrm{mL}^{-1}$ conjugated polymer P3HT methylbenzene solution for $12 \mathrm{hr}$ to uptake P3HT. Next, PEDOT:PSS layer was spin-coated onto the bulk-heterojunction. Finally, about $50 \mathrm{~nm}$ thickness of Pt electrodes were deposited on the top of the PEDOT: PSS layer by thermal evaporation under vacuum.

1. Swanson, R. M. Applied physics. Photovoltaics power up. Science 324, 891-892 (2009).

2. Singh, S., Mahalingam, H. \& Singh, P. K. Polymer-supported titanium dioxide photocatalysts for environmental remediation: A review. Appl. Catal. A: General 462-463, 178-195 (2013).

3. Chandrasekaran, J. et al. Hybrid solar cell based on blending of organic and inorganic materials-An overview. Rew. Sust. Energy Rev. 15, 1228-1238 (2011).

4. Gao, F., Ren, S. \& Wang, J. The renaissance of hybrid solar cells: progresses, challenges, and perspectives. Energy Environ. Sci. 6, 2020-2040 (2013).

5. Shoaee, S., Briscoe, J., Durrant, J. R. \& Dunn, S. Acoustic enhancement of polymer/ZnO nanorod photovoltaic device performance. Adv. Mater. 26, 263-268 (2014)

6. Lee, J. et al. High-efficiency panchromatic hybrid Schottky solar cells. Adv. Mater 25, 256-260 (2013)

7. Wang, X. et al. High-performance metal-free solar cells using stamp transfer printed vapor phase polymerized poly(3,4-ethylenedioxythiophene) top anodes. Adv. Funct. Mater. 22, 1454-1460 (2012).

8. Zhou, Y., Eck, M. \& Krüger, M. Bulk-heterojunction hybrid solar cells based on colloidal nanocrystals and conjugated polymers. Energy Environ. Sci. 3, 1851-1864 (2010).

9. Günes, S., Neugebauer, H. \& Sariciftci, N. S. Conjugated polymer-based organic solar cells. Chem. Rev. 107, 1324-1338 (2007).

10. Tisdale, W. A. et al. Hot-electron transfer from semiconductor nanocrystals. Science 328, 1543-1547 (2010).

11. Kamat, P. V. Photovoltaics: capturing hot electrons. Nat. Chem. 2, 809-810 (2010).

12. Conibeer, G. et al. Modelling of hot carrier solar cell absorbers. Sol. Energy Mater. Sol. Cells 94, 1516-1521 (2010).

13. Gabor, N. M. et al. Hot carrier-assisted intrinsic photoresponse in graphene. Science 334, 648-652 (2011).

14. Tielrooij, K. J. et al. Photoexcitation cascade and multiple hot-carrier generation in graphene. Nat. Phys. 9, 248-252 (2013).

15. Li, W., Roelofs, W. S., Wienk, M. M. \& Janssen, R. A. Enhancing the photocurrent in diketopyrrolopyrrole-based polymer solar cells via energy level control. J. Am. Chem. Soc. 134, 13787-13795 (2012).

16. Yang, B. et al. Tuning the energy level offset between donor and acceptor with ferroelectric dipole layers for increased efficiency in bilayer organic photovoltaic cells. Adv. Mater. 24, 1455-1460 (2012).

17. Gong, X. et al. Bulk heterojunction solar cells with large open-circuit voltage: Electron transfer with small donor-acceptor energy offset. Adv. Mater. 23, 2272-2277 (2011).

18. Xie, Y. et al. Improved performance of dye-sensitized solar cells by trace amount Cr-doped $\mathrm{TiO}_{2}$ photoelectrodes. J. Power Sources 224, 168-173 (2013).

19. Zwilling, V., Aucouturier, M. \& Darque-Ceretti, E. Anodic oxidation of titanium and TA6V alloy in chromic media. An electrochemical approach. Electrochim. Acta 45, 921-929 (1999).

20. Melhem, H. et al. Direct photocurrent generation from nitrogen doped $\mathrm{TiO}_{2}$ electrodes in solid-state dye-sensitized solar cells: Towards optically-active metal 
oxides for photovoltaic applications. Sol. Energy Mater. Sol. Cells 117, 624-631 (2013).

21. Kim, Y. S., Yu, B.-K., Kim, D.-Y. \& Kim, W. B. A hybridized electron-selective layer using $\mathrm{Sb}$-doped $\mathrm{SnO}_{2}$ nanowires for efficient inverted polymer solar cells. Sol. Energy Mater. Sol. Cells 95, 2874-2879 (2011).

22. Wang, J. et al. Application of $\mathrm{Y}_{2} \mathrm{O}_{3}: \mathrm{Er}^{3+}$ nanorods in dye-sensitized solar cells. ChemSusChem 5, 1307-1312 (2012).

23. Wu, J. et al. Dual functions of $\mathrm{YF}_{3}: \mathrm{Eu}^{3+}$ for improving photovoltaic performance of dye-sensitized solar cells. Sci. Rep. 3, 2058 (2013).

24. Wu, J. et al. Enhancement of the photovoltaic performance of dye-sensitized solar cells by doping $\mathrm{Y}_{0.78} \mathrm{Yb}_{0.20} \mathrm{Er}_{0.02} \mathrm{~F}_{3}$ in the Photoanode. Adv. Energy Mater. 2, 78-81 (2012)

25. Haase, M. \& Schafer, H. Upconverting nanoparticles. Angewandte Chemie 50, 5808-5829 (2011).

26. Eliseeva, S. V. \& Bunzli, J. C. Lanthanide luminescence for functional materials and bio-sciences. Chem. Soc. Rev. 39, 189-227 (2010).

27. Cheng, F. et al. Enhancing the short-circuit current and efficiency of organic solar cells using $\mathrm{MoO}_{3}$ and CuPc as buffer layers. Sol. Energy Mater. Sol. Cells 95, 2914-2919 (2011).

28. Zhang, F. J. et al. Inverted small molecule organic solar cells with Ca modified ITO as cathode and $\mathrm{MoO}_{3}$ modified $\mathrm{Ag}$ as anode. Sol. Energy Mater. Sol. Cells $\mathbf{9 4}$, 2416-2421 (2010).

29. Cheng, F. et al. Enhancing the performance of P3HT:ICBA based polymer solar cells using $\mathrm{LiF}$ as electron collecting buffer layer and UV-ozone treated $\mathrm{MoO}_{3}$ as hole collecting buffer layer. Sol. Energy Mater. Sol. Cells 110, 63-68 (2013).

30. Xing, G. et al. Long-range balanced electron- and hole-transport lengths in organic-inorganic $\mathrm{CH}_{3} \mathrm{NH}_{3} \mathrm{PbI}_{3}$. Science 342, 344-347 (2013).

31. Stranks, S. D. et al. Electron-hole diffusion lengths exceeding 1 micrometer in an organometal trihalide perovskite absorber. Science 342, 341-344 (2013).

32. Burschka, J. et al. Sequential deposition as a route to high-performance perovskite-sensitized solar cells. Nature 499, 316-319 (2013).

33. Kroon, R., Lenes, M., Hummelen, J. C., Blom, P. W. M. \& de Boer, B. Small bandgap polymers for organic solar cells(Polymer material development in the last 5 years). Polym. Rev. 48, 531-582 (2008).

34. Wu, J.-S. et al. Dithienocarbazole-based ladder-type heptacyclic arenes with silicon, carbon, and nitrogen bridges: Synthesis, molecular properties, field-effect transistors, and photovoltaic applications. Adv. Funct. Mater. 22, 1711-1722 (2012)

35. Clarke, T. M. \& Durrant, J. R. Charge photogeneration in organic solar cells. Chem. Rev. 110, 6736-6767 (2010).

36. Halls, J. J. M. et al. Charge- and energy-transfer processes at polymer/polymer interfaces: A joint experimental and theoretical study. Phys. Rev. B 60, 5721-5727 (1999).

37. Brabec, C. J. et al. A low-bandgap semiconducting polymer for photovoltaic devices and infrared emitting diodes. Adv. Funct. Mater. 12, 709-712 (2002)

38. Shaw, P. E., Ruseckas, A. \& Samuel, I. D. W. Exciton diffusion measurements in poly(3-hexylthiophene). Adv. Mater. 20, 3516-3520 (2008).

39. Zhitomirsky, D., Voznyy, O., Hoogland, S. \& Sargent, E. H. Measuring charge carrier diffusion in coupled colloidal quantum dot solids. ACS Nano 7, 5282-5290 (2013)

40. Xing, G. C. et al. Long-range balanced electron- and hole-transport lengths in organic-inorganic $\mathrm{CH}_{3} \mathrm{NH}_{3} \mathrm{PbI}_{3}$. Science 342, 344-347 (2013).

41. Guo, J. M., Ohkita, H., Benten, H. \& Ito, S. Charge generation and recombination dynamics in poly(3-hexylthiophene)/fullerene blend films with different regioregularities and morphologies. J. Am. Chem. Soc. 132, 6154-6164 (2010).

42. Gratzel, M. Photoelectrochemical cells. Nature 414, 338-344 (2001).

43. Liu, Y., Summers, M. A., Edder, C., Fréchet, J. M. J. \& McGehee, M. D. Using resonance energy transfer to improve exciton harvesting in organic-inorganic hybrid photovoltaic cells. Adv. Mater. 17, 2960-2964 (2005).

44. Scharber, M. C. et al. Design rules for donors in bulk-heterojunction solar cellstowards 10\% energy-conversion efficiency. Adv. Mater. 18, 789-794 (2006).
45. Szarko, J. M. et al. Photovoltaic function and exciton/charge transfer dynamics in a highly efficient semiconducting copolymer. Adv. Funct. Mater. 24, 10-26 (2014).

46. Ohkita, H. \& Ito, S. Transient absorption spectroscopy of polymer-based thin-film solar cells. Polymer 52, 4397-4417 (2011).

47. Marsh, R. A., Hodgkiss, J. M., Albert-Seifried, S. \& Friend, R. H. Effect of annealing on P3HT:PCBM charge transfer and nanoscale morphology probed by ultrafast spectroscopy. Nano Lett. 10, 923-930 (2010).

48. Klimov, V. I. Spectral and dynamical properties of multiexcitons in semiconductor nanocrystals. Annu. Rev. Phys. Chem. 58, 635-673 (2007)

49. Koppe, M. et al. Charge carrier dynamics in a ternary bulk heterojunction system consisting of $\mathrm{P} 3 \mathrm{HT}$, fullerene, and a low bandgap polymer. Adv. Energy Mater. 3, 949-958 (2013).

50. Sun, W. F., Zeng, Q. H. \& Yu, A. B. Calculation of noncontact forces between silica nanospheres. Langmuir 29, 2175-2184 (2013).

51. Sun, W. F., Zeng, Q. H., Yu, A. B. \& Kendall, K. Calculation of normal contact forces between silica nanospheres. Langmuir 29, 7825-7837 (2013).

52. Sun, W. F. The dynamic effect on mechanical contacts between nanoparticles. Nanoscale 5, 12658-12669 (2013).

53. Lin, Y. Y., Chu, T. H., Chen, C. W. \& Su, W. F. Improved performance of polymer/ $\mathrm{TiO}_{2}$ nanorod bulk heterojunction photovoltaic devices by interface modification. Appl. Phys. Lett. 92, 053312 (2008).

54. Lin, Y., Wei, Q., Qian, G., Yao, L. \& Watkins, J. J. Morphology control in $\mathrm{TiO}_{2}$ nanorod/polythiophene composites for bulk heterojunction solar cells using hydrogen bonding. Macromolecules 45, 8665-8673 (2012).

55. Wu, J. et al. An all-solid-state dye-sensitized solar cell-based poly(N-alkyl-4-vinylpyridine iodide) electrolyte with efficiency of 5.64\%. J. Am. Chem. Soc. 130, 11568-11569 (2008).

56 . Wu, J. et al. Crystal morphology of anatase titania nanocrystals used in dyesensitizedsolar cells. Cryst. Growth Des. 8, 247-252 (2007).

\section{Acknowledgments}

The authors gratefully acknowledge the financial support of the Natural Science Foundation of China (61366003), the science and technology project of the education department of Jiangxi Province, China (GJJ12449, GJJ14533), Nanchang Hangkong University Doctor Program (EA201108333).

\section{Author contributions}

X.J. synthesized the materials. Q.H.L., W.F.S. and X.D.H. characterized the materials. Y.L. and Z.H.C. fabricated and characterized the devices. Q.H.L. and W.F.S. guided the experimental work. X.J. and T.H.W. analyzed the spectroscopic data. X.J., Q.H.L. and W.F.S. wrote the manuscript with contributions from all authors.

\section{Additional information}

Supplementary information accompanies this paper at http://www.nature.com/ scientificreports

Competing financial interests: The authors declare no competing financial interests. How to cite this article: Jin, X. et al. Energy level control: toward an efficient hot electron transport. Sci. Rep. 4, 5983; DOI:10.1038/srep05983 (2014).

This work is licensed under a Creative Commons Attribution-NonCommercialNoDerivs 4.0 International License. The images or other third party material in this article are included in the article's Creative Commons license, unless indicated otherwise in the credit line; if the material is not included under the Creative Commons license, users will need to obtain permission from the license holder in order to reproduce the material. To view a copy of this license, visit http:// creativecommons.org/licenses/by-nc-nd/4.0/ 